\title{
Absorptive capacity and its impact on innovation and performance: findings from SEM and fsQCA
}

\author{
Sonia Cruz-Ros ${ }^{1} \cdot$ Diana L. Guerrero-Sánchez ${ }^{2} \cdot$ Maria-Jose Miquel-Romero $^{3}$ (D)
}

Received: 2 March 2018 / Accepted: 27 November 2018 / Published online: 6 December 2018

(c) Springer-Verlag GmbH Germany, part of Springer Nature 2018

\begin{abstract}
Innovation can provide sustainable competitive advantages to service companies that consider the absorption of external knowledge a key strategic issue. Using the four dimensions of absorptive capacity, this study examined the impact of absorptive capacity on innovation in service delivery processes and explored how this innovation influences business performance. Structural equation modeling (PLS-SEM) and fuzzy-set qualitative comparative analysis (fsQCA) were applied to a sample of 134 companies drawn from the Colombian tourism sector. The results of the SEM indicate that innovation in service delivery processes is positively influenced by two of the four dimensions of absorptive capacity: knowledge transformation and knowledge exploitation. Also, innovation in service delivery processes encourages outstanding performance and mediates the relationship between absorptive capacity and business performance. These findings are supported by the results of the fsQCA. Furthermore, although the SEM results indicate that knowledge exploitation has the greatest direct influence on innovation, the fsQCA results suggest that knowledge assimilation and transformation are necessary conditions for companies to outperform competitors.
\end{abstract}

Keywords Absorptive capacity · Innovation · fsQCA · SEM - Business performance

Maria-Jose Miquel-Romero

maria.j.miquel@uv.es

Sonia Cruz-Ros

sonia.cruz@uv.es

Diana L. Guerrero-Sánchez

dlguerrero@unicatolica.edu.co

1 Departamento de Dirección de Empresas - Juan José Renau, Faculty of Economics, University of Valencia, Avda Los Naranjos, s/n, 46022 Valencia, Spain

2 Fundación Universitaria Lumén Gentium-Unicatólica, Facultad de Ciencias Empresariales, Universidad de Cali, Carrera 122 \# 12-459, Cali, Valle del Cauca, Colombia

3 Departamento de Comercialización e Investigación de Mercados, Faculty of Economics, University of Valencia, Avda Los Naranjos, s/n, 46022 Valencia, Spain 


\section{JEL Classification M10 · M31}

\section{Introduction}

Today's economy is characterized by globalization in turbulent and dynamic environments, rapid technological development, and constant change in consumer tastes. In this context, firms cannot afford to be passive. Not only must they exploit their knowledge to its full potential, but they must also innovate to meet the demands of the market and thus remain competitive (Bruni and Verona 2009). Successfully leveraging knowledge enhances operational efficiency and improves innovation performance. This innovation reduces risks, costs, and time, thereby increasing margins (Fritsch and Meschede 2001). Accordingly, organizational knowledge constitutes an important competitive advantage for firms.

One way of strengthening organizational knowledge is through the firm's ability to absorb external knowledge from the competitive environment (Kogut and Zander 1992). This ability is referred to in the literature as absorptive capacity (ACAP) (Cohen and Levinthal 1990). Firms cannot rely exclusively on their internal knowledge to compete in such a hostile environment (Koçoglu et al. 2015). They must combine internal knowledge with the acquisition and use of external knowledge so that they can adapt to meet market demands.

Innovation in services, which include intangible resources associated with service delivery design (Verma and Jayasimha 2014), has emerged as a way of accelerating business growth and boosting profits (Berry et al. 2006).

In the tourism sector, knowledge has repeatedly been cited as a determinant of innovation (Martinez-Roman et al. 2015) because it determines the innovative capability of companies in the sector (Hjalager 2002). Despite extensive literature on ACAP and innovation and on innovation and performance in different contexts (for a meta-analysis, see Zou et al. 2018), more research is needed for the tourism sector. Although research by Hjalager (2010) has already been discussed, Camisón and Monfort-Mir (2012) highlighted the differentiating characteristics of innovation processes in the tourism industry. Consequently, Najda-Janoszka and Kopera (2014) justified the need for further research on this topic for the tourism sector.

Building on these arguments and focusing on the tourism sector, this study examines how ACAP influences firms' capability to innovate in the service delivery process and how this kind of innovation, in turn, enhances the performance of firms relative to competitors. The studies that have linked ACAP to innovation and/ or performance in the tourism sector (e.g., Elbaz et al. 2018; Milwood and Zach 2016; Nieves et al. 2014; Thomas and Wood 2015) have yielded inconclusive findings. First, the choice of whether to measure ACAP as a multidimensional or unidimensional construct and its operationalization for the posited relationships differ in different studies. Second, some of these studies, such as the one by Milwood and Zach (2016), have linked ACAP to innovation performance measured, for example, in terms of sales without considering its influence on innovation itself. However, in studies that have considered the concept of innovation processes, innovation is addressed from a more generic perspective, where "technology investments are the 
anchor of mainstream process innovation, sometimes in combination with reengineered layouts for manual work operations" (Hjalager 2010, p. 2).

Accordingly, the contribution of this study is twofold. First, the study enriches the ACAP literature and the literature on innovation in service delivery processes (ISDP). This contribution is highly relevant because tourism organizations depend more heavily on external sources of knowledge than firms in other sectors do (Thomas and Wood 2014), and as Arshad and Su (2015) note, knowledge of ISDP (rather than innovation processes in general) is scarce. This study identifies the effect of each dimension of ACAP on ISDP and the mediating role of ISDP on business performance, thereby differentiating between the role of innovation itself and its effects on business performance. Second, our empirical method enabled us to compare and contrast results in a rigorous fashion. While the primary method, structural model estimation using partial least squares (SEM-PLS) allowed us to test our hypotheses and analyze the mediation effect, a secondary analysis using fuzzy-set qualitative comparative analysis (fsQCA) supported our initial results. Ritala et al. (2016) and more recently Kraus et al. (2018) report the increasingly widespread use and prevalence of fsQCA in research on innovation in the area of business and management.

\section{Literature review}

The ACAP literature is abundant, perhaps reflecting the relevance of ACAP as a crucial dynamic capability in knowledge-based competition (Zahra and George 2002). Scholars broadly agree that Cohen and Levinthal (1989) were the first to identify and define ACAP. Some years later following a rigorous review of the literature, Zahra and George (2002) concluded that the term ACAP was ambiguous because of the breadth of definitions, components, antecedents, and consequences that they identified. Based on a review of numerous proposals in the literature, Zahra and George (2002, p. 186) defined ACAP as "a set of organizational routines and processes by which firms acquire, assimilate, transform, and exploit knowledge to produce a dynamic organizational capability". For Zahra and George (2002), the four capabilities that are cited in the definition correspond to the four dimensions of ACAP. These dimensions can be placed into two groups: potential ACAP (comprising acquisition and assimilation) and realized ACAP (transformation and exploitation). Distinguishing between potential and realized ACAP requires an implicit assumption that acquiring valuable external knowledge does not guarantee that this knowledge will be exploited. In developing a strong ACAP, the firm must be able to lay the foundations for creating and applying newly acquired knowledge (Robertson et al. 2012) and developing capabilities that encourage the coexistence of existing and acquired knowledge (Kogut and Zander 1992). Other issues such as prior knowledge base, organizational factors (Jansen et al. 2005; Vega-Jurado et al. 2008), and the company's external orientation (Harrington and Guimaraes 2005) can condition ACAP. 
According to Chesbrough and Crowther (2006), ACAP is a precondition for innovation. It encourages access to and use of external knowledge in organizational processes, leading to greater innovation capability through the application of this knowledge within the firm (Cohen and Levinthal 1990; Engelman et al. 2017; Fosfuri and Tribó 2008; Nieto and Quevedo 2005).

In the tourism sector, numerous studies have focused on innovation (e.g., Aldebert et al. 2011; Fraj et al. 2015; Grissemann et al. 2013; Martinez-Roman et al. 2015; Najda-Janoszka and Kopera 2014; Rodriguez et al. 2014), but few have examined how ACAP influences innovation (e.g., Milwood and Zach 2016; Nieves et al. 2014; Thomas and Wood 2014, 2015). Some of these studies have adopted Zahra and George's (2002) approach, positing that potential ACAP influences realized ACAP and that realized ACAP is the type of ACAP that influences innovation. However, Koçoglu et al. (2015, p. 113) posited that the sequential relationship between the dimensions of ACAP has "the risk of masking the individual effects of the components [of ACAP] on the firm innovativeness". In fact, studies have considered the influence of each dimension of ACAP at the same level rather than conceptualizing ACAP as a sequential process (e.g., Ali et al. 2016; Jansen et al. 2005; Liu et al. 2017). Accordingly, in this study, we posit that each of the four dimensions of ACAP positively influences the capability to innovate in the service delivery process.

As summarized by Koçoglu et al. (2015), ACAP encourages innovation for several reasons. First, it encourages the development of collaboration networks with external actors such as customers, suppliers, dealers, or even competitors (Murovec and Prodan 2009). These networks give firms access to more information. Second, it encourages the development of skills to identify this information or knowledge (Haro-Domínguez et al. 2007). Finally, it helps firms recognize what is new about this external knowledge and what is not (internal knowledge) and helps firms assimilate this knowledge (Abecassis-Moedas and MahmoudJouini 2008). As Cohen and Levinthal (1990, p. 129) affirm, "an organization needs prior related knowledge to assimilate and use new knowledge". Although this reflection is derived from the area of product innovation, we argue that it is equally valid for innovation in services, specifically in service delivery processes, because knowledge is an intangible resource. We therefore propose the following hypotheses:

H1 The capability to acquire external knowledge positively affects innovation in service delivery processes.

H2 The capability to assimilate external knowledge positively affects innovation in service delivery processes.

Through the mechanisms that align external knowledge with existing organizational knowledge, the internal capabilities that encourage innovation are transformed and exploited (Zhou and Li 2012). The use of this new knowledge in organizational processes allows the firm to orient its strategies toward innovation 
(Engelman et al. 2017; Escribano et al. 2009; Forés and Camisón 2016; Nieto and Quevedo 2005). We therefore propose the following hypotheses:

H3 The capability to transform external knowledge positively affects innovation in service delivery processes.

H4 The capability to exploit external knowledge positively affects innovation in service delivery processes.

Numerous studies have linked different types of innovation to business performance, highlighting a positive relationship between these two variables. For example, scholars have analyzed the effect of innovation on profitability (Walker 2004), sales, gross profit margin and firm growth (Govindarajan and Kopalle 2006), cash flows and future profitability (Sorescu et al. 2007), and return on sales and return on assets (Kostopoulos et al. 2011). We therefore propose the following hypothesis:

H5 Innovation in service delivery processes positively affects performance.

Figure 1 depicts our theoretical model and hypotheses.

Finally, considering the direct influence of ACAP on innovation performance identified in several studies (e.g., Milwood and Zach 2016), we complement our analysis (Fig. 1) by investigating the possible mediating role of ISDP on the relationships between the dimensions of ACAP and business performance.

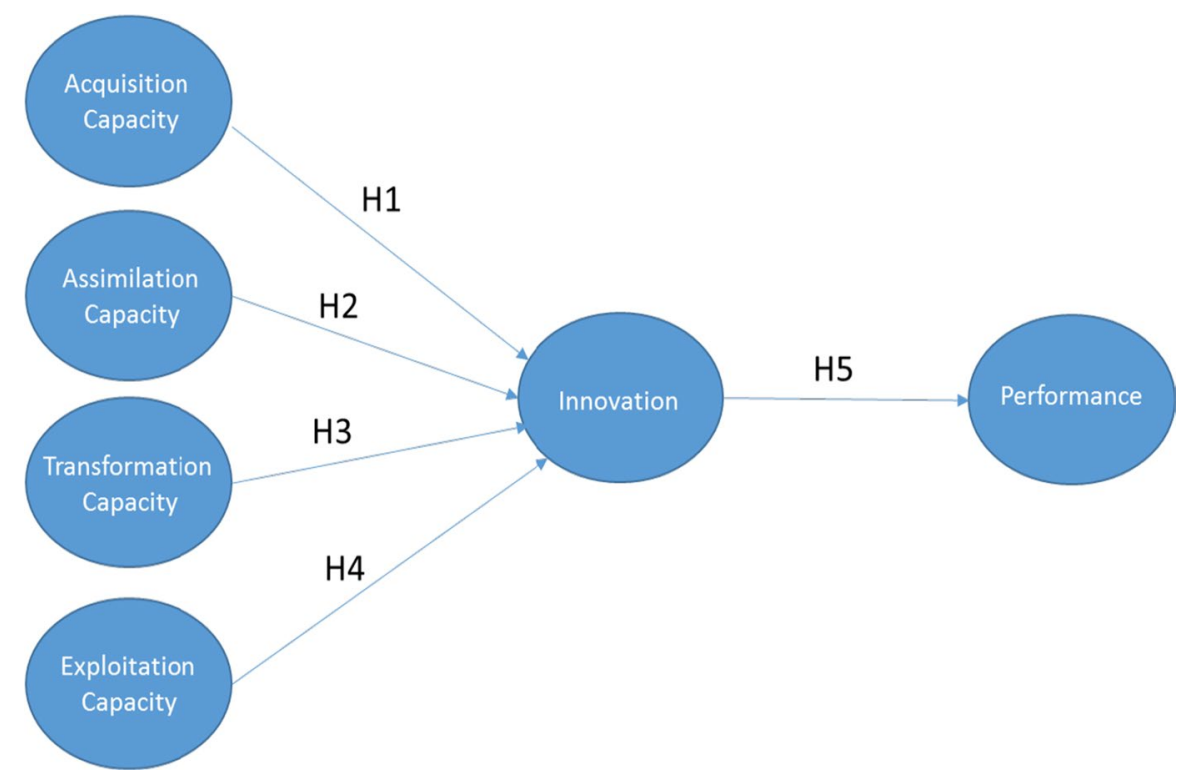

Fig. 1 Theoretical model 


\section{Methodology}

To test our hypotheses, we conducted a study of firms from the tourism sector. The Colombian tourism sector was chosen as the study context for two reasons. First, the tourism sector has been a dynamic, growing industry within the Colombian economy in recent years. Second, in contrast to other sectors, very few studies of this sector have been conducted in a Colombian context.

Starting with a list of tourism companies appearing in the national tourism register and the Colombian chamber of commerce, an online questionnaire was sent to the managers, heads, or directors of marketing of 1000 firms. A stratified sampling procedure based on type of firm (hotel, travel agency, restaurant, or transport company) was used. We received 196 questionnaires, of which 134 were valid. The sampling error was therefore $\pm 8 \%$ for a confidence level of $95 \%$. Data collection took place between January and March 2017.

Five-point Likert scales $(1=$ totally disagree; $5=$ totally agree $)$ extracted from the literature were used to collect data from respondents. To measure ACAP, we used Flatten et al.'s (2015) 14-item scale. This scale has been widely used by scholars. The ISDP was measured with 5 items from the Oslo Manual (2005). Finally, to measure performance, respondents indicated their firms' performance relative to the performance of competitors, using four items adapted from the studies by Pérez-Cabañero et al. (2015) and Reinartz et al. (2004).

The statistical method used to test our hypotheses and analyze the mediating effect of ISDP was partial least squares structural equation modeling (PLS-SEM). For small samples such as the sample used in this study, PLS works better than other statistical techniques. As Reinartz et al. (2009) and Henseler et al. (2014) have shown, PLS has better convergence behavior for small sample sizes than covariance-based SEM does.

Subsequently, to check the results and consider other possible paths for tourism firms to outperform competitors, the data were again analyzed using fsQCA, an analysis technique developed by Ragin (2000). The goal was to compare and contrast the SEM results with those of fsQCA. FsQCA has three key characteristics that offer advantages over traditional, regression-based techniques. These advantages provide a new approach to interpreting results. The first key characteristic is the possibility of asymmetrical relationships among causal conditions (Elliot 2013). Second, fsQCA admits equifinality, which means that multiple paths or solutions may produce the same outcome. Third, fsQCA embraces causal complexity, which means that not all conditions must be present for the outcome to occur; different combinations of causal conditions may lead to the same outcome. According to Tho and Trang (2015), scholars can use qualitative comparative analysis (QCA) solutions to support a regression-based framework. 


\section{Results}

\subsection{Psychometric properties and common method bias}

Before testing our hypotheses, we evaluated the measurement model. It was not necessary to eliminate any items from the scales. For all items, the loadings on their respective factors were significant. The standardized loadings were greater than 6 (Bagozzi and Yi 1988). As Table 1 illustrates, all scales met the criteria for reliability. Table 1 also displays the data used to verify convergent validity. For all constructs, the average variance extracted (AVE) value was greater than the accepted threshold of .5 (Fornell and Larcker 1981), confirming convergent validity.

Following Fornell and Larcker's (1981) indications, we confirmed that the covariance between constructs was lower than the corresponding AVE, implying the absence of discriminant validity problems (Table 1 ).

Finally, to control for common method bias, we conducted Harman's single-factor test (Podsakoff et al. 2003). We entered all variables into an exploratory factor analysis and examined the unrotated factor solution. We checked that more than one factor emerged from the factor analysis and that the first factor did not account for the majority of the covariance between the measures. The exploratory factor analysis yielded five factors with eigenvalues that were greater than 1 , and the first factor accounted for only $20.9 \%$ of the variance.

\subsection{Hypothesis testing using PLS-SEM}

The theoretical model was tested based on the magnitude and significance of the path coefficients $(\beta)$, the proportion of variance explained $\left(\mathrm{R}^{2}\right)$ by the dependent variables, and their predictive relevance $\left(\mathrm{Q}^{2}\right)$. According to the $\mathrm{R}^{2}$ values in Table 2 , the four dimensions of ACAP explained a moderate proportion of the ISDP $\left(\mathrm{R}^{2}=.545\right)$ and performance $\left(\mathrm{R}^{2}=.265\right)$. All values for the Stone-Geisser $\left(\mathrm{Q}^{2}\right)$ test were greater

Table 1 Psychometric properties of the scales

\begin{tabular}{|c|c|c|c|c|c|c|c|c|c|}
\hline \multicolumn{3}{|c|}{ Reliability and convergent validity } & & \multicolumn{6}{|c|}{ Discriminant validity } \\
\hline AVE & $\mathrm{CR}$ & Cronbach' $\alpha$ & & $\mathrm{AC} 1$ & $\mathrm{AC} 2$ & AC3 & AC4 & ISDP & Perf \\
\hline .627 & .832 & .712 & $\mathrm{AC} 1$ & .792 & & & & & \\
\hline .620 & .866 & .799 & $\mathrm{AC} 2$ & .607 & .787 & & & & \\
\hline .627 & .870 & .803 & $\mathrm{AC} 3$ & .489 & .578 & .792 & & & \\
\hline .687 & .867 & .771 & $\mathrm{AC} 4$ & .482 & .608 & .646 & .829 & & \\
\hline .698 & .920 & .891 & ISDP & .489 & .565 & .601 & 694 & .836 & \\
\hline .793 & .938 & .908 & Perf & .251 & .330 & .326 & .308 & .515 & .890 \\
\hline
\end{tabular}

Correlations between constructs appear below the diagonal; the square root of the average variance extracted (AVE) appears in bold on the diagonal

$A C 1$ acquisition capacity, AC2 assimilation capacity, AC3 transformation capacity, AC4 exploitation capacity, ISDP innovation in service delivery process, Perf performance, $A V E$ average variance extracted, $C R$ composite reliability 
Table 2 Structural equation modeling: causal relations analysis

\begin{tabular}{|c|c|c|c|c|}
\hline Structural relations & & $\beta$ & t value (bootstrap) & Test \\
\hline H1 & $\begin{array}{l}\text { Acquisition capac- } \\
\text { ity } \rightarrow \text { ISDP }\end{array}$ & .109 & 1.719 & Rejected \\
\hline $\mathrm{H} 2$ & $\begin{array}{l}\text { Assimilation capac- } \\
\text { ity } \rightarrow \text { ISDP }\end{array}$ & .116 & 1.206 & Rejected \\
\hline H3 & $\begin{array}{l}\text { Transformation capac- } \\
\text { ity } \rightarrow \text { ISDP }\end{array}$ & .192 & $2.217 * *$ & Accepted \\
\hline H4 & $\begin{array}{l}\text { Exploitation capac- } \\
\text { ity } \rightarrow \text { ISDP }\end{array}$ & .447 & $5.289 * * *$ & Accepted \\
\hline H5 & ISDP $\rightarrow$ performance & .515 & $6.887 * * *$ & Accepted \\
\hline $\mathrm{R}^{2}$ (innovation) $=.545$ & & $\mathrm{Q}^{2}$ (innovation) $=.367$ & & \\
\hline $\mathrm{R}^{2}$ (performance $)=.265$ & & $\mathrm{Q}^{2}($ performance $)=.202$ & & \\
\hline
\end{tabular}

$* * * p<.01 ; * * p<.05$ [based on a one-tailed student's t (4999) distribution]

than 0 , confirming the adequate predictive quality of the model and indicating that the estimates were stable.

To test our hypotheses, we used bootstrapping with 5000 subsamples (Hair et al. 2011; Henseler et al. 2009) to analyze the significance of the path coefficients. The significance of the proposed relationships, reflected by the t values, supports hypotheses $\mathrm{H} 3, \mathrm{H} 4$, and $\mathrm{H} 5$ but leads to the rejection of hypotheses $\mathrm{H} 1$ and $\mathrm{H} 2$ (Table 2).

The results indicate that the only dimensions of ACAP that exert a positive significant effect on ISDP are the firm's capability to transform knowledge and exploit knowledge (hypotheses $\mathrm{H} 3$ and $\mathrm{H} 4$, respectively). The influence of knowledge exploitation was the larger of the two. Thus, our analysis indicates that a greater capability to transform knowledge is associated with greater ISDP and that a greater capability to exploit knowledge is likewise associated with greater ISDP. Similarly, greater ISDP is associated with better performance (H5).

\subsection{The mediating role of innovation in service delivery processes}

After testing the hypotheses, we checked the mediating role of ISDP in the proposed model. Because the effects of only two of the four dimensions of ACAP were statistically significant, we checked the mediating role only for those dimensions (Table 3). We therefore estimated all direct, indirect, and total effects on the variables included in the model.

As Table 3 shows, the capacity of transformation of knowledge had a significant total effect on performance. When the mediator (ISDP) was introduced, the path from the capacity of transformation of knowledge to performance was no longer significant. The variable accounted for (VAF) index, which determines the size of the indirect effect with respect to the total effect, suggested full mediation because it was greater than $80 \%$ (Hair et al. 2016). When we analyzed the mediating role of ISDP in the relationship between knowledge exploitation capacity and business performance, the results also indicated full mediation. 
Table 3 Mediation test

\begin{tabular}{|c|c|c|c|c|c|c|c|}
\hline & \multicolumn{2}{|c|}{ Total effect } & \multicolumn{2}{|c|}{ Direct effect } & \multicolumn{3}{|l|}{ Indirect effect } \\
\hline & Coef. & $t$ value & Coef. & $t$ value & Point estimate & $t$ value & VAF $(\%)$ \\
\hline $\mathrm{AC} 3 \rightarrow$ Perf & $.327 * *$ & 3.472 & $0.026^{\mathrm{ns}}$ & .254 & & & \\
\hline$(\mathrm{AC} 3 \rightarrow \mathrm{ISDP}) *(\mathrm{ISDP} \rightarrow$ Perf $)$ & & & & & $.300 * *$ & 4.458 & 92 \\
\hline AC4 $\rightarrow$ Perf & $.498 * *$ & 5.227 & $0.095^{\mathrm{ns}}$ & .856 & & & \\
\hline$(\mathrm{AC} 4 \rightarrow \mathrm{ISDP}) *(\mathrm{ISDP} \rightarrow$ Perf $)$ & & & & & $.403 * *$ & 4.582 & 81 \\
\hline
\end{tabular}

$V A F$ variance accounted for, $A C 3$ transformation capacity, AC4 exploitation capacity, ISDP innovation in service delivery process, Perf performance

$* * p<.001 ; n s$ not significant [based on t (4999), one-tailed test]

\subsection{Analysis of the data using fsQCA}

FsQCA describes each case as a combination of causal conditions and an outcome. The outcome is the result of interest. In our analysis, the outcome was outperforming competitors. The causal conditions are the factors that potentially lead to the outcome. In our analysis, the causal conditions were the implementation of each dimension of ACAP and ISDP.

FsQCA admits data from metric scales, but the causal conditions and the outcome should each be represented by a single item. Therefore, each construct was embodied by a single item, which was calculated using the arithmetic mean. In fsQCA, variables must be transformed into sets to enable the analysis of combinations of causal sets that constitute a subset of the outcome set. Variables are calibrated into sets using fsQCA software. Following Ragin's (2008a) recommendations, we transformed the variables into calibrated sets using three substantively meaningful thresholds: full membership (1), full non-membership (0), and a crossover point (.5). This crossover point represents the point of maximum ambiguity. Specifying the original values for these three breakpoints allows the software to calibrate all remaining scores. The calibration followed the procedure employed by Ordanini et al. (2014), which we adjusted for five-point scales as follows: the full membership threshold was set to 4 , the full non-membership threshold was set to 2 , and the crossover point was set to 3 .

Following calibration, fsQCA explores how membership of cases to causal conditions is linked to membership to the outcome (Ragin 2008b). FsQCA thus identifies necessary and sufficient causal conditions for the outcome to occur. A causal condition is sufficient if, by itself, it produces the outcome, whereas it is necessary if that condition must be present for the outcome to occur (Ragin 2000, 2008b). We distinguished between core and peripheral conditions, defining "causal coreness in terms of the strength of the evidence relative to the outcome, not connectedness to other configurational elements" (Fiss 2011, p. 403).

Table 4 displays the intermediate solution. The data in Table 4 indicate that several configurations are sufficient for companies to outperform competitors. The four solutions together explain $86 \%$ of companies that outperform competitors. 
Table 4 Sufficient conditions for outperforming competitors

\begin{tabular}{|c|c|c|c|c|}
\hline \multirow[t]{2}{*}{ Configuration } & \multicolumn{4}{|c|}{ Solutions } \\
\hline & 1 & 2 & 3 & 4 \\
\hline Service delivery process innovation & ○ & & $\varnothing$ & \\
\hline Knowledge acquisition & & $\bullet$ & $\varnothing$ & $\varnothing$ \\
\hline Knowledge assimilation & & $\bullet$ & $\varnothing$ & $\bullet$ \\
\hline Knowledge transformation & ○ & ○ & ○ & $\varnothing$ \\
\hline Knowledge exploitation & $\bullet$ & & $\varnothing$ & $\varnothing$ \\
\hline Raw coverage & .76 & .75 & .05 & .06 \\
\hline Unique coverage & .09 & .09 & .00 & .01 \\
\hline Consistency & .89 & .87 & .80 & .98 \\
\hline Overall solution coverage: & .86 & & & \\
\hline Overall solution consistency: & .86 & & & \\
\hline
\end{tabular}

Black circles $\bullet$ indicate the presence of a condition; circles with "/" $(\varnothing)$ indicate its absence; blank spaces indicate neutrality (i.e., no pattern of presence or absence was identified). Large circles indicate core conditions, and small ones, peripheral conditions

These solutions met the minimum overall consistency and overall coverage criteria that are suggested in the literature (.60 for coverage and .75 for consistency when analyzing sufficient conditions) (Ragin 2000).

The fsQCA results support the results of the SEM analysis. Solution 1 (the solution with the most firms) suggests that companies that outperform competitors also report ISDP, knowledge transformation, and knowledge exploitation. These three constructs were observed to have significant relationships in the SEM analysis. According to solution 1, ISDP and knowledge transformation are core conditions for outperforming competitors.

The fsQCA also identified other patterns for companies that outperformed competitors. Outstanding performance was also identified in companies with knowledge acquisition, assimilation, and transformation (solution 2), companies with knowledge transformation but without the other dimensions of ACAP and without ISDP capability (solution 3), and companies that innovate in service delivery processes and have knowledge assimilation but that do not have knowledge acquisition, transformation, or exploitation (solution 4).

Next, we considered the necessity of the causal conditions for outstanding performance. Knowledge assimilation (consistency $=.92$; coverage $=.85$ ) and knowledge transformation (consistency $=.91$; coverage $=.85$ ) were observed to be necessary conditions for companies to outperform competitors. The values of consistency and coverage for these causal conditions surpassed the minimum values (Ragin 2006) that are required for necessity (.90 and .75 for consistency and coverage, respectively). 


\section{Discussion and conclusion}

This study extends our knowledge of how the dimensions of ACAP relate to ISDP and performance in the tourism sector. Based on Zahra and George (2002), we adopted a different approach to considering how each dimension of ACAP relates to ISDP, consistent with Koçoglu et al.'s (2015) reasoning. We hypothesized a direct influence of the four dimensions of ACAP on ISDP. Our PLS results show that realized ACAP (i.e., knowledge transformation and exploitation) positively and significantly influences ISDP. The results of the SEM show that, of the two dimensions of ACAP that affect ISDP, knowledge exploitation exerts the greatest influence. In contrast, the analysis failed to show that potential ACAP (i.e., knowledge acquisition and assimilation) exerts a significant influence on ISDP. The results also indicate a positive and significant relationship between ISDP and performance. These results are not fully consistent with those of Ali et al. (2016) outside the tourism industry. In their study, knowledge transformation capability was the only ACAP dimension that did not directly influence process innovation. However, in some sense, our results are consistent with those reported by Cepeda-Carrion et al. (2012) or Milwood and Zach (2016). They adopted the traditional conceptualization of ACAP proposed by Zahra and George (2002), suggesting that realized ACAP is the form of ACAP that has a direct effect on business innovation and that potential ACAP enables the exploitation and transformation of new ideas into innovation. Several studies that have examined product innovation have likewise shown that firms with the highest levels of realized ACAP are most effective at developing new products (e.g., Jansen et al. 2005; Lichtenthaler 2009).

A major contribution of this study is the use of ISDP as a mediating variable in the relationship between the dimensions of ACAP and performance. This approach had not been adopted in previous studies. ISDP plays a full mediating role in the relationships between transformation capacity and performance, and between exploitation capacity and performance.

Moreover, in this study, we employed two different methods, SEM and fsQCA, lending greater robustness and depth to our research. The fsQCA results support the SEM results. The results of the fsQCA indicate that firms that outperform competitors have realized ACAP and ISDP. FsQCA also identified knowledge transformation as a necessary condition. Thus, to achieve outstanding performance, firms must be capable of transforming knowledge acquired from the external environment. Although the SEM failed to show that potential ACAP exerts a significant influence, the fsQCA did identify knowledge assimilation as a necessary condition for outperforming competitors. Consistent with Milwood and Zach (2016), this finding suggests that learning how external knowledge fits into the existing structures of tourism companies also plays a relevant role in improving business performance. Additionally, we used fsQCA to consider the existence of different paths of variables for firms achieving outstanding performance. This approach is supported by Koçoglu et al.'s (2015) views regarding the role of the dimensions of ACAP.

Our findings have practical implications. Tourism firms should strengthen their ACAP and ISDP. Doing so could lead to competitive advantages that would 
improve their business performance. As this study shows, one way to strengthen this form of innovation is to act upon two dimensions of ACAP, namely knowledge transformation and exploitation, although the firm must also assimilate external knowledge because doing so was observed to be a necessary condition to outperform competitors. Given that, in this sector, consumers are included in innovation processes because of the close consumer-producer interaction (Hjalager 2010), a key factor seems to be the firm's capability to refine existing routines and procedures or develop new ones that enable new, not necessarily external, knowledge to be considered. Sound management of ACAP also leads to better business performance through the mediating role of ISDP.

Accordingly, tourism firms must be aware of their ACAP, and managers should be flexible by facilitating and encouraging the necessary changes within the organization to enable access to knowledge that is useful and applicable to ISDP. Another important aspect relates to the factors that generate and determine this ACAP. Factors such as the company's external orientation, experience in searching for knowledge, organizational structures, leadership, and motivation should also be considered.

This study has certain limitations. These include the sample size. It would have been better to use a larger sample because, among other things, we are aware of the criticisms of PLS. Other SEM-based statistical techniques could have been used. Although PLS path modeling has been widely used not only in management research but also in virtually all social science disciplines, there is considerable controversy over its use.

Other limitations include the specificity of the study's geographical focus, as well as the lack of control variables. Although the similarity of the results yielded by the two methods in this study provide a certain measure of control, specific control variables such as firm size and age could be considered in future research. Moreover, studies of this sector that have considered the variables examined in this study have typically focused on one specific type of tourism company (e.g., only hotel firms). In contrast, our study was based on a highly varied sample of companies. Another issue relates to the subjective business performance measure used.

Future research could consider objective data to measure business performance. Additionally, future studies should examine some of the antecedents of potential ACAP that are highlighted in the literature to clarify the non-significant influence of this type of ACAP in our model. Aspects such as R\&D cooperation and experience in knowledge search could be considered. Finally, building upon the ideas discussed by Roig-Tierno et al. (2018), it may be of interest to study how coopetition potentially increases the different forms of ACAP and, accordingly, influences their effect on innovation.

\section{References}

Abecassis-Moedas C, Mahmoud-Jouini SB (2008) Absorptive capacity and source-recipient complementarity in designing new products: an empirically derived framework. J Prod Innov Manage 25:473-490 
Aldebert B, Dang RJ, Longhi C (2011) Innovation in the tourism industry: the case of tourism. Tour Manage 32:1204-1213

Ali M, Kan KAS, Sarstedt M (2016) Direct and configurational paths of absorptive capacity and organizational innovation to successful organizational performance. J Bus Res 69:5317-5323

Arshad AM, Su Q (2015) Interlinking service delivery innovation and service quality: a conceptual framework. J Appl Bus Res 31:1807

Bagozzi RP, Yi Y (1988) On the evaluation of structural equation models. J Acad Mark Sci 16:74-94

Berry LL, Parish JT, Cadwallader S, Shankar V, Dotzel T (2006) Creating new markets through service innovation. MIT Sloan Manage Rev 47:56-63

Bruni DS, Verona G (2009) Dynamic marketing capabilities in science-based firms: an exploratory investigation of the pharmaceutical industry. Brit J Manage 20:S101-S117

Camisón C, Monfort-Mir VM (2012) Measuring innovation in tourism from the Schumpeterian and the dynamic-capabilities perspectives. Tour Manage 33:776-789

Cepeda-Carrion G, Cegarra-Navarro JG, Jiménez-Jiménez D (2012) The effect of absorptive capacity on innovativeness: context and information systems capability as catalysts. Brit J Manage 23:110-129

Chesbrough H, Crowther AK (2006) Beyond high tech: early adopters of open innovation in other industries. R\&D Manage 36:229-236

Cohen WM, Levinthal DA (1989) Innovation and learning: the two faces of R\&D. Econ J 99:569-596

Cohen WM, Levinthal DA (1990) Absorptive capacity: a new perspective on learning and innovation. Adm Sci Q 35:128-152

Elbaz AM, Agag GM, Alkathiri NA (2018) How ability, motivation and opportunity influence travel agents performance: the moderating role of absorptive capacity. J knowl Manag 22:119-141

Elliot T (2013) Fuzzy set qualitative comparative analysis. http://www.socsci.uci.edu/ sgsa/docs/fsQCA _thomas_elliot.pdf. Accessed July 2016

Engelman RM, Fracasso EM, Schnidt S, Zen AC (2017) Intellectual capital, absorptive capacity and product innovation. Manag Decis 55:474-490

Escribano A, Fosfuri A, Tribó JA (2009) Managing external knowledge flows: the moderating role of absorptive capacity. Res Policy 38:96-105

Fiss PC (2011) Building better causal theories: a fuzzy set approach to typologies in organization research. Acad Manage J 54:393-420

Flatten T, Adams D, Brettel M (2015) Fostering absorptive capacity through leadership: a cross-cultural analysis. J World Bus 50:519-534

Forés B, Camisón C (2016) Does incremental and radical innovation performance depend on different types of knowledge accumulation capabilities and organizational size? J Bus Res 69:831-848

Fornell C, Larcker DF (1981) Evaluating structural equation models with unobservable variables and measurement error. J Mark Res 18:39-50

Fosfuri A, Tribó JA (2008) Exploring the antecedents of potential absorptive capacity and its impact on innovation performance. Omega 36:173-187

Fraj E, Matute J, Melero I (2015) Environmental strategies and organizational competitiveness in the hotel industry: the role of learning and innovation as determinants of environmental success. Tour Manage 46:30-42

Fritsch M, Meschede M (2001) Product innovation, process innovation, and size. Rev Ind Organ 19:335-350

Govindarajan V, Kopalle PK (2006) Disruptiveness of innovations: measurement and an assessment of reliability and validity. Strateg Manage J 27:189-199

Grissemann U, Plank A, Brunner-Sperdin A (2013) Enhancing business performance of hotels: the role of innovation and customer orientation. Int J Hosp Manag 33:347-356

Hair JF, Ringle CM, Sarstedt M (2011) PLS-SEM: indeed a silver bullet. J Mark Theory Practice 19:137-149

Hair JF, Hult GTM, Ringle C, Sarstedt M (2016) A primer on partial least squares structural equation modeling (PLS-SEM). Sage Publications, Thousand Oaks

Haro-Domínguez MC, Arias-Aranda D, Llorens-Montes FJ, Ruiz-Moreno A (2007) The impact of absorptive capacity on technological acquisitions engineering consulting companies. Technovation 27:417-425

Harrington SJ, Guimaraes T (2005) Corporate culture, absorptive capacity and IT success. Inf Organ 15:39-63

Henseler J, Ringle CM, Sinkovics RR (2009) The use of partial least squares path modeling in international marketing. Adv Int Mark 20:277-320 
Henseler J, Dijkstra TK, Sarstedt M, Ringle CM, Diamantopoulos A, Straub DW, Calantone RJ (2014) Common beliefs and reality about PLS: comments on Rönkkö and Evermann (2013). Organ Res Methods 17:182-209

Hjalager AM (2002) Repairing innovation defectiveness in tourism. Tour Manage 23:465-474

Hjalager AM (2010) A review of innovation research in tourism. Tour Manage 31:1-12

Jansen J, Van den Bosch FAJ, Volberda HW (2005) Managing potential and realized absorptive capacity: how do organizational antecedents matter? Acad Manage J 48:999-1015

Koçoglu I, Akgün AE, Keskin H (2015) The differential relationship between absorptive capacity and product innovativeness: a theoretically derived framework. Int Bus Res 8:108-120

Kogut B, Zander U (1992) Knowledge of the firm, combinative capabilities, and the replication of technology. Organ Sci 3:383-397

Kostopoulos K, Papalexandris A, Papachroni M, Ioannou G (2011) Absorptive capacity, innovation, and financial performance. J Bus Res 64:1335-1343

Kraus S, Ribeiro-Soriano D, Schüssler M (2018) Fuzzy-set qualitative comparative analysis (fsQCA) in entrepreneurship and innovation research-the rise of a method. Int Entrep Manag J 14:15-33

Lichtenthaler U (2009) Absorptive capacity, environmental turbulence, and the complementarity of organizational learning processes. Acad Manage J 52:822-846

Liu X, Shen M, Ding W, Zhao X (2017) Tie strength, absorptive capacity and innovation performance in Chinese manufacturing industries. Nankai Bus Rev Int 8:475-494

Martinez-Roman JA, Tamayo JA, Gamero J, Romero JE (2015) Innovativeness and business performances in tourism SMEs. Ann Tour Res 54:118-135

Milwood P, Zach F (2016) Innovative Tourism Destinations: Collaboration Culture and Absorptive Capacity. Tourism Travel and Research Association: Advancing Tourism Research Globally

Murovec N, Prodan I (2009) Absorptive capacity, its determinants, and influence on innovation output: cross cultural validation of the structural model. Technovation 29:859-872

Najda-Janoszka M, Kopera S (2014) Exploring barriers to innovation in tourism industry-the case of southern region of Poland. Procedia Soc Behav Sci 110:190-201

Nieto M, Quevedo P (2005) Absorptive capacity, technological opportunity, knowledge spillovers, and innovative effort. Technovation 25:1141-1157

Nieves J, Quintana A, Osorio J (2014) Knowledge-based resources and innovation in the hotel industry. Int J Hosp Manag 38:65-73

Oecd E (2005) Oslo manual. Guidelines for collecting and interpreting innovation data

Ordanini A, Parasuraman A, Rubera G (2014) When the recipe is more important than the ingredients a qualitative comparative analysis (QCA) of service innovation configurations. J Serv Res 17:134-149

Pérez-Cabañero A, Cruz-Ros S, González-Cruz T (2015) The contribution of dynamic marketing capabilities to service innovation and performance. Int J Bus Environ 7:61-78

Podsakoff PM, MacKenzie SB, Lee JY, Podsakoff NP (2003) Common method biases in behavioural research: a critical review of the literature and recommended remedies. J Appl Psychol 88:879-903

Ragin CC (2000) Fuzzy-set social science. The University of Chicago Press, Chicago

Ragin CC (2006) Set relations in social research: evaluating their consistency and courage. Polit Anal $14: 291-310$

Ragin CC (2008a) Qualitative comparative analysis using fuzzy sets (fsQCA). In: Benoit R, Ragin C (eds) Configurational comparative analysis. Sage Publication, Thousand Oaks, pp 87-121

Ragin CC (2008b) Redesigning social inquiry: fuzzy sets and beyond. University of Chicago Press, Chicago

Reinartz W, Krafft M, Hoyer WD (2004) The customer relationship management process: its measurement and impact on performance. J Mark Res 41:293-305

Reinartz WJ, Haenlein M, Henseler J (2009) An empirical comparison of the efficacy of covariance based and variance-based SEM. Int J of Res Mark 26:332-344

Ritala P, Kraus S, Bouncken RB (2016) Introduction to coopetition and innovation: contemporary topics and future research opportunities. J Technol Manage 71:1-9

Robertson PL, Casali GL, Jacobson D (2012) Managing open incremental process innovation: absorptive capacity and distributed learning. Res Policy 41:822-832

Rodriguez I, Williams AM, Hall CM (2014) Tourism innovation policy: implementation and outcomes. Ann Tour Res 49:76-93

Roig-Tierno N, Kraus S, Cruz S (2018) The relation between coopetition and innovation/entrepreneurship. Rev Manag Sci 12:379-383 
Sorescu AB, Chandy RK, Prabhu JC (2007) Why some acquisitions do better than others: product capital as a driver of long-term stock returns. J Mark Res 44:57-72

Tho ND, Trang NTM (2015) Can knowledge be transferred from business schools to business organizations through in-service training students? SEM and fsQCA findings. J Bus Res 68:1332-1340

Thomas R, Wood E (2014) Innovation in tourism: re-conceptualising and measuring the absorptive capacity of the hotel sector. Tour Manage 45:39-48

Thomas R, Wood E (2015) The absorptive capacity of tourism organisations. Ann Tour Res 54:84-99

Vega-Jurado J, Gutiérrez-Gracia A, Fernández-de-Lucio I (2008) Analyzing the determinants of firm's absorptive capacity: beyond R\&D. R\&d Manage 38:392-405

Verma R, Jayasimha KR (2014) Service delivery innovation architecture: an empirical study of antecedents and outcomes. IIMB Manag Rev 26(2):105-121

Walker RM (2004) Innovation and organizational performance: evidence and a research agenda. In: Advanced institute of management research working paper series, 002 London, June

Zahra SA, George G (2002) Absorptive capacity: a review, reconceptualization, and extension. Acad Manage Rev 27:185-203

Zhou KZ, Li CB (2012) How knowledge affects radical innovation: knowledge base, market knowledge acquisition, and internal knowledge sharing. Strateg Manage J 33:1090-1102

Zou T, Ertug G, George G (2018) The capacity to innovate: a meta-analysis of absorptive capacity. Innovation 20:87-121 